\title{
Novel Synthetic Monothiourea Aspirin Derivatives Bearing Alkylated Amines as Potential Antimicrobial Agents
}

\author{
Norsyafikah Asyilla Nordin, ${ }^{1}$ Tchan Wei Chai, ${ }^{1}$ Bee Ling Tan, ${ }^{1}$ Ching Liang Choi, \\ Ainaa Nadiah Abd Halim, ${ }^{1}$ Hasnain Hussain, ${ }^{2}$ and Zainab Ngaini ${ }^{1}$ \\ ${ }^{1}$ Department of Chemistry, Faculty of Resource Science and Technology, Universiti Malaysia Sarawak, \\ 94300 Kota Samarahan, Sarawak, Malaysia \\ ${ }^{2}$ Department of Molecular Biology, Faculty of Resource Science and Technology, Universiti Malaysia Sarawak, \\ 94300 Kota Samarahan, Sarawak, Malaysia
}

Correspondence should be addressed to Zainab Ngaini; nzainab@unimas.my

Received 19 August 2016; Revised 4 November 2016; Accepted 5 December 2016; Published 22 January 2017

Academic Editor: Artur M. S. Silva

Copyright (c) 2017 Norsyafikah Asyilla Nordin et al. This is an open access article distributed under the Creative Commons Attribution License, which permits unrestricted use, distribution, and reproduction in any medium, provided the original work is properly cited.

A new series of aspirin bearing alkylated amines moieties 1-12 were synthesised by reacting isothiocyanate with a series of aniline derivatives in overall yield of $16-56 \%$. The proposed structures of all the synthesised compounds were confirmed using elemental analysis, FTIR, and ${ }^{1} \mathrm{H}$ and ${ }^{13} \mathrm{C}$ NMR spectroscopy. All compounds were evaluated for antibacterial activities against $E$. coli and S. aureus via turbidimetric kinetic and Kirby Bauer disc diffusion method. Compound 5 bearing meta $-\mathrm{CH}_{3}$ substituent showed the highest relative inhibition zone diameter against tested bacteria compared to ortho and para substituent. Furthermore, aspirin derivatives bearing shorter chains exhibited better bacterial inhibition than longer alkyl chains.

\section{Introduction}

Over the centuries many antibacterial drugs were used to treat bacterial-causing diseases including food poisoning, pneumonia and intestinal infection $[1,2]$. The improper usage of these drugs has caused the bacteria to evolve into drug resistant bacteria which reduce the effectiveness of the drugs [3]. The continuing development of new antimicrobial agents therefore remains a priority [1].

Aspirin is a widely used medicine for antipyretic, analgesic, and anti-inflammatory [4]. The demand of aspirin and its derivatives for other biological properties is increasing due to its availability and reactivity as precursor for further modification via corresponding carboxyl group [5]. Aspirin derivatives have shown antibacterial activities against Bacillus subtilis, Escherichia coli, Staphylococcus aureus, and Pseudomonas aeruginosa [6, 7]. Other significant biological properties of aspirin derivatives are reported for antitumor, anticancer, antifungal, and antimicrobial agents $[5,7-9]$.
We have previously reported on aspirin with thiourea moieties bearing amino acid and aromatic amines with excellent antibacterial properties. The lipophilicity of the aromatic ring has contributed to the enhancement of the biological activities [5]. Thiourea is a type of reactive precursor due to the presence of $\mathrm{C}=\mathrm{S}, \mathrm{C}=\mathrm{O}$, and $\mathrm{NH}$ moieties which are essential in biological activities [10]. Several biological activities reported on thiourea are antibacterial, antifungal, anticancer, antitubercular, antimicrobial, and anti-HIV activities [11-17]. The synthesis of thiourea derivatives has also received great attraction due to their diverse application such as in textile processing and heavy metals extraction as chelating agent and agriculture as plant growth regulator [18-20].

\section{Results and Discussion}

Aspirin derivatives 1-12 with aryl side chain bearing alkyl substituents were prepared from the reaction of acetoxybenzoyl isothiocyanate with a series of commercially available 


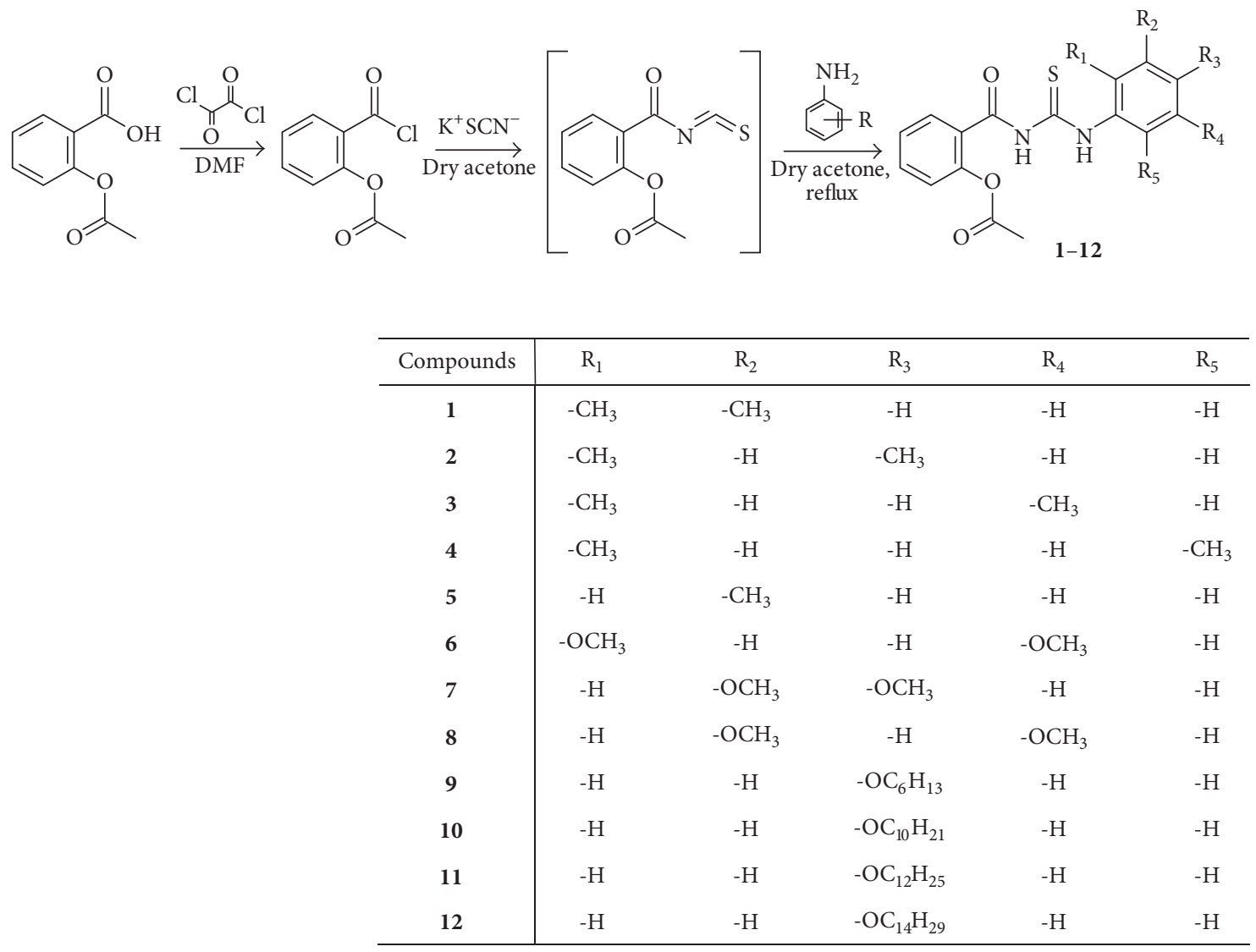

Scheme 1: Synthesis of aspirin derivatives 1-12.

methyl and methoxy anilines and alkylated anilines prepared via Williamson etherification. A general synthesis of 1-12 is depicted in Scheme 1. Characteristic spectroscopic data of the synthesised compounds are provided in the supplementary data in Supplementary Material available online at https://doi.org/10.1155/2017/2378186. Aspirin was added to oxalyl chloride solution in dichloromethane followed by addition of few drops of dimethylformamide [21]. The mixture was stirred for $1 \mathrm{~h}$ at room temperature and added dropwise to $\mathrm{KSCN}$ in dry acetone to form $\mathrm{KCl}$ and filtered [5]. Aniline derivatives in dry acetone were then added to the filtrate and refluxed for $4 \mathrm{~h}$. Crushed ice was added to the mixture to form precipitate. The crude was recrystallised in ethanol to obtain 1-12 in moderate yields (16-56\%). The synthesis of thiourea could form urethane as side product which contributed to the low product yield [22]. The structures of all the synthesised compounds were elucidated using elemental analysis, FTIR, and ${ }^{1} \mathrm{H}$ and ${ }^{13} \mathrm{C}$ NMR spectroscopy.

The FTIR spectra of $\mathbf{1 - 1 2}$ showed absorption bands at $3375-3213 \mathrm{~cm}^{-1}$ attributed to $v(\mathrm{~N}-\mathrm{H})$, while peaks corresponding to long alkyl chain were observed at 2933$2843 \mathrm{~cm}^{-1}$. The successful formations of $\mathbf{1}-\mathbf{1 2}$ were supported by the disappearance of peak at $2000 \mathrm{~cm}^{-1}$ resulting from the conversion of -NCS to -NH. The absorption peaks at 1791$1760 \mathrm{~cm}^{-1}$ and $1675-1611 \mathrm{~cm}^{-1}$ were attributed to $v(\mathrm{C}=\mathrm{O})$ ester and $v(\mathrm{C}=\mathrm{O})$ amide, respectively. The aryl groups were observed at $1528-1500 \mathrm{~cm}^{-1}$. The presence of $v(\mathrm{C}-\mathrm{N})$ and $v(\mathrm{C}=\mathrm{S})$ was indicated by the absorption band at 1089$1125 \mathrm{~cm}^{-1}$ and $890-810 \mathrm{~cm}^{-1}$, respectively [16].

${ }^{1} \mathrm{H}$ NMR spectra of $\mathbf{1 - 1 2}$ showed the presence of methyl groups at $0.83-2.33 \mathrm{ppm}$, whereas the methoxy groups were observed at $3.72-3.96 \mathrm{ppm}$ due to the electronegativity of oxygen attached to the carbon [23]. The resonance peaks at $6.42-8.50 \mathrm{ppm}$ were assigned to the aryl groups. The peaks at $11.53-11.65 \mathrm{ppm}$ and $11.96-12.90 \mathrm{ppm}$ corresponded to $\mathrm{CSNH}$ and $\mathrm{CONH}$, respectively. The deshielding effect of electron-withdrawing carbonyl group and thiocarbonyl group has shifted the signal to downfield region [24]. In ${ }^{13} \mathrm{C}$ NMR, methyl substituents were represented at 13.931.9 ppm, while the methoxy group were deshielded at 55.4$68.2 \mathrm{ppm}$ due to the electronegativity of oxygen [23]. The presence of peaks at 98.3 and $160.3 \mathrm{ppm}$ was attributed to aromatic carbons, whereas $\mathrm{C}=\mathrm{O}$ ester, $\mathrm{C}=\mathrm{O}$ amide, and $\mathrm{C}=\mathrm{S}$ were indicated by the signals at $164.2-166.7 \mathrm{ppm}, 168.3-$ $169.1 \mathrm{ppm}$, and 176.9-180.0 ppm, respectively. Thiocarbonyl and carbonyl group appeared at higher chemical shift due to formation of intramolecular hydrogen bonding and different environment and conformations [23, 25].

Prior to the synthesis of $\mathbf{9 - 1 2}, \mathbf{1 3}-\mathbf{1 6}$ were prepared as precursors via Williamson etherification of 4-hydroxyl acetanilide with bromoalkanes in the presence of $\mathrm{K}_{2} \mathrm{CO}_{3}$ in dry acetone. The mixture was refluxed for $48 \mathrm{~h}$ to obtain white 

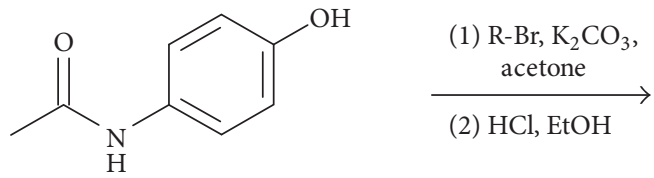<smiles>[R]Oc1ccc(N)cc1</smiles>

$13-16$

$$
\begin{aligned}
& \text { 13, } \mathrm{R}=\mathrm{C}_{6} \mathrm{H}_{15} \\
& \text { 14, } \mathrm{R}=\mathrm{C}_{10} \mathrm{H}_{21} \\
& \text { 15, } \mathrm{R}=\mathrm{C}_{12} \mathrm{H}_{25} \\
& \text { 16, } \mathrm{R}=\mathrm{C}_{14} \mathrm{H}_{29}
\end{aligned}
$$

\begin{tabular}{|c|c|c|c|c|}
\hline \multirow[b]{2}{*}{ Compounds } & \multicolumn{2}{|c|}{ E. coli } & \multicolumn{2}{|c|}{ S. aureus } \\
\hline & Zone of inhibition (mm) & $\begin{array}{c}\text { Relative inhibition zone } \\
\text { diameter (\%) }\end{array}$ & Zone of inhibition $(\mathrm{mm})$ & $\begin{array}{c}\text { Relative inhibition zone } \\
\text { diameter }(\%)\end{array}$ \\
\hline 1 & 7.3 & 45.6 & 8.0 & 72.7 \\
\hline 2 & 7.7 & 48.1 & 10.7 & 97.3 \\
\hline 3 & 10.5 & 65.6 & - & - \\
\hline 4 & - & - & - & - \\
\hline 5 & 10.7 & 66.9 & 11.3 & $>100$ \\
\hline 6 & - & - & - & - \\
\hline 7 & 8.5 & 53.1 & 10.3 & 93.6 \\
\hline 8 & 9.3 & 58.1 & 10.3 & 93.6 \\
\hline 9 & 8.0 & 50.0 & - & - \\
\hline 10 & - & - & - & - \\
\hline 11 & - & - & - & - \\
\hline 12 & - & - & - & - \\
\hline Aspirin & - & - & - & - \\
\hline DMSO & - & - & - & - \\
\hline Ampicillin & 16.0 & 100 & 11.0 & 100 \\
\hline
\end{tabular}

Scheme 2: Preparation of alkylated anilines 13-16.

TABLE 1: Antibacterial activities of 1-12 in comparison to aspirin and control.

precipitate and hydrolysed in ethanol- $\mathrm{HCl}(1: 1)$ to form $13-$ 16 (Scheme 2) [26-28]. Spectroscopy analysis showed that all peaks corresponded to the proposed structure.

Antibacterial activities of 1-12 were initially performed against E. coli ATCC 25922 and S. aureus S48/81 via turbidimetric kinetic method [5]. All compounds experienced solubility limitation in the assays media which hindered the inhibition studies. Alternatively, disc diffusion method was performed on 1-12 [29]. Ampicillin (positive control) was used as standard drug, while dimethyl sulfoxide (DMSO) was used as negative control with aspirin as a reference. The antibacterial activities of $\mathbf{1 - 1 2}$ are shown in Table 1. The inhibition of E. coli and S. aureus was calculated via inhibition zone of $\mathbf{1 - 1 2}$ in comparison to the inhibition zone of ampicillin. The inhibition zones of all compounds are provided in the supplementary data.

In comparison to aspirin, 1-12 showed moderate to good activities towards the growth of $E$. coli, except 4, 6, and 1012. The presence of $\mathrm{C}=\mathrm{O}, \mathrm{C}=\mathrm{S}$, and $\mathrm{NH}$ groups is envisaged to contribute to the antibacterial activities and formed interaction with the carboxyl and phosphate group of the bacterial surface [10]. The location and type of substituents in the compounds contribute to the inhibition activities. Compound 5 with meta substituted $-\mathrm{CH}_{3}$ gave better inhibition to the bacterial growth with the highest percentage relative inhibition zone diameter (66.9\%). Compounds 13, 7, and $\mathbf{8}$ with disubstituted methyl and methoxy group showed lower inhibition based on zone diameter percentage (45.6-65.6\%). The presence of methyl and methoxy groups has induced steric repulsion and decreased the activities. The steric hindrance at both ortho positions in the phenyl group affected the efficacy of antibacterial effect which explained that E. coli was insusceptible to 4 [30]. The presence of bulky methoxy substituents at ortho position in $\mathbf{6}$ prevented the compound to act on the active sites of the bacteria [31]. The introduction of shorter alkyl chain, $n=6$ (9), afforded moderate activity, while no activity was observed for 10-12 with $n=10-14$. The longer alkyl chain, which is similar to the component of the cell wall, decreased the penetration onto the cell membrane [32]. This also suggested that shorter alkyl chain as in $\mathbf{9}$ is the optimum length for bacterial inhibition [27]. 
Antibacterial activities were also demonstrated against $S$. aureus. Compound 5 gave better inhibition than that of the standard drug (ampicillin), while 1, 2, 7, and 8 showed 72.7-97.3\% inhibition. The presence of a methyl substituent at meta position in $\mathbf{5}$ gave better penetration into the bacterial cell wall via suitable binding [33]. On the other hand, no activity was observed for 3, 4, 6, and 9-12. Growth inhibition on $S$. aureus is lesser compared to $E$. coli because $S$. aureus has thicker cell wall that causes ineffectiveness in membrane penetration [34].

\section{Experimental}

Aspirin, oxalyl chloride, potassium thiocyanate, 2,3-dimethylaniline, 2,4-dimethylaniline, 2,5-dimethylaniline, 2,6-dimethylaniline, 2-toluidine, 2,5-dimethoxyaniline, 3,4-dimethoxyaniline, 3,5-dimethoxyaniline, 4-hydroxyl acetanilide, and 1-bromoalkanes were obtained from Merck. All other reagents were used without further purification; nevertheless the acetone was distilled before being used.

Melting points were determined on Stuart SMP3 using open tube capillary method. FTIR spectra $\left(v / \mathrm{cm}^{-1}\right)$ were recorded as $\mathrm{KBr}$ pellets on Perkin Elmer 1605 FTIR Spectrophotometer. ${ }^{1} \mathrm{H}$ NMR and ${ }^{13} \mathrm{CNMR}$ spectra were recorded on JEOL ECA 500 at $500 \mathrm{MHz}\left({ }^{1} \mathrm{H}\right)$ and $125 \mathrm{MHz}\left({ }^{13} \mathrm{C}\right)$ with the chemical shift reported relative to DMSO- $\mathrm{d}_{6}$ and $\mathrm{CDCl}_{3}$ as the standard reference and chemical shift values were expressed in $\delta$ ppm.

3.1. General Procedure for the Preparation of Aspirin Bearing Alkylated Amines (1-12). Aspirin ( $2 \mathrm{mmol}$ ) was added to oxalyl chloride solution in dichloromethane followed by addition of few drops of dimethylformamide. The mixture was stirred for $1 \mathrm{~h}$ at room temperature and was added dropwise to KSCN $(2 \mathrm{mmol})$ in dry acetone $(10 \mathrm{~mL})$. The mixture was stirred at room temperature to form precipitate and it was filtered to remove the solid. Aryl amine $(2 \mathrm{mmol})$ in $10 \mathrm{~mL}$ of dry acetone was then added to the filtrate and the reaction mixture was refluxed for $4 \mathrm{~h}$. The mixture was cooled to room temperature and filtered. The filtrate was transferred into a beaker and crushed ice was added to it. The solid formed was recrystallised in ethanol to obtain 112. Supplementary data for FTIR, ${ }^{1} \mathrm{H}$, and ${ }^{13} \mathrm{C}$ NMR spectra of the synthesised compounds are available online.

[2-[(2,3-Dimethylphenyl)carbamothioylcarbamoyl]phenyl] Acetate (1). Compound $\mathbf{1}$ was obtained as a white solid. Yield: 0.2786 g (41\%); m.p. 133-136 ${ }^{\circ}$; (Found: C, 62.88; H, 5.30; $\mathrm{N}, 7.96 . \mathrm{C}_{18} \mathrm{H}_{18} \mathrm{O}_{3} \mathrm{~N}_{2} \mathrm{~S}$ Requires $\mathrm{C}, 63.14 ; \mathrm{H}, 5.30 ; \mathrm{N}, 8.18 \%$ ); v $3213(\mathrm{~N}-\mathrm{H}), 1760$ ( $\mathrm{C}=\mathrm{O}$ ester), $1673(\mathrm{C}=\mathrm{O}$ amide), 1525 $(\mathrm{Ar}-\mathrm{C}), 1188(\mathrm{C}-\mathrm{N}), 876(\mathrm{C}=\mathrm{S}) . \delta_{\mathrm{H}}\left(\mathrm{DMSO}_{6}\right) 1.90(3 \mathrm{H}, \mathrm{s}$, $\left.\mathrm{CH}_{3}\right), 2.19\left(3 \mathrm{H}, \mathrm{s}, \mathrm{CH}_{3}\right), 2.26\left(3 \mathrm{H}, \mathrm{s}, \mathrm{CH}_{3}\right), 7.03-7.97(7 \mathrm{H}, \mathrm{m}$, Ar-H), $11.65(1 \mathrm{H}, \mathrm{s}, \mathrm{NH}), 12.22(1 \mathrm{H}, \mathrm{s}, \mathrm{NH}) . \delta_{\mathrm{C}}\left(\mathrm{DMSO}_{6} \mathrm{~d}_{6}\right)$ $13.9\left(\mathrm{CH}_{3}\right), 20.1\left(\mathrm{CH}_{3}\right), 20.8\left(\mathrm{CH}_{3}\right), 123.2,124.9,125.6,126.1$, $126.8,128.8,130.0,132.5,133.3,136.8,137.4,148.2$ (Ar-C), 166.6 $(\mathrm{C}=\mathrm{O}), 169.0(\mathrm{C}=\mathrm{O})$ and $180.0(\mathrm{C}=\mathrm{S})$.
[2-[(2,4-Dimethylphenyl)carbamothioylcarbamoyl]phenyl] Acetate (2). Compound 2 was obtained as yellowish white solid. Yield: $0.1117 \mathrm{~g}(16 \%)$; m.p. $115-118^{\circ} \mathrm{C}$; (Found: C, 63.00; H, 5.10; N, 7.88. $\mathrm{C}_{18} \mathrm{H}_{18} \mathrm{O}_{3} \mathrm{~N}_{2} \mathrm{~S}$ Requires $\mathrm{C}, 63.14 ; \mathrm{H}, 5.30 ; \mathrm{N}$, 8.18\%); $v 3381(\mathrm{~N}-\mathrm{H}), 1775$ ( $\mathrm{C}=\mathrm{O}$ ester), 1663 ( $\mathrm{C}=\mathrm{O}$ amide), 1523 (Ar-C), $1189(\mathrm{C}-\mathrm{N}), 810(\mathrm{C}=\mathrm{S}) . \delta_{\mathrm{H}}\left(\mathrm{DMSO}_{\mathrm{d}}\right) 2.20(3 \mathrm{H}$, $\left.\mathrm{s}, \mathrm{CH}_{3}\right), 2.29\left(3 \mathrm{H}, \mathrm{s}, \mathrm{CH}_{3}\right), 2.31\left(3 \mathrm{H}, \mathrm{s}, \mathrm{CH}_{3}\right), 7.04-7.73(7 \mathrm{H}, \mathrm{m}$, Ar-H), $11.62(1 \mathrm{H}, \mathrm{s}, \mathrm{NH}), 11.96(1 \mathrm{H}, \mathrm{s}, \mathrm{NH}) \delta_{\mathrm{C}}\left(\mathrm{DMSO}_{-} \mathrm{d}_{6}\right) 17.5$ $\left(\mathrm{CH}_{3}\right), 20.6\left(\mathrm{CH}_{3}\right), 20.8\left(\mathrm{CH}_{3}\right), 123.2,126.0,126.5,126.8,130.0$, 131.0, 133.2, 133.3, 134.3, 136.5, 148.2 (Ar-C), 166.6 (C=O), 169.0 $(\mathrm{C}=\mathrm{O})$ and $179.7(\mathrm{C}=\mathrm{S})$.

[2-[(2,5-Dimethylphenyl)carbamothioylcarbamoyl]phenyl] Acetate (3). Compound 3 was obtained as yellowish white solid. Yield: $0.2620 \mathrm{~g}$ (38\%); m.p. $119-122^{\circ} \mathrm{C}$; (Found: C, 63.10; H, 5.45; N, 8.02. $\mathrm{C}_{18} \mathrm{H}_{18} \mathrm{O}_{3} \mathrm{~N}_{2} \mathrm{~S}$ Requires $\mathrm{C}, 63.14 ; \mathrm{H}, 5.30 ; \mathrm{N}$, $8.18 \%) ; v 3352(\mathrm{~N}-\mathrm{H}), 1773$ ( $\mathrm{C}=\mathrm{O}$ ester), 1663 ( $\mathrm{C}=\mathrm{O}$ amide), 1524 (Ar-C), $1150(\mathrm{C}-\mathrm{N}), 890(\mathrm{C}=\mathrm{S}) . \delta_{\mathrm{H}}\left(\mathrm{DMSO}_{6}\right) 1.90(3 \mathrm{H}$, $\left.\mathrm{s}, \mathrm{CH}_{3}\right), 2.19\left(3 \mathrm{H}, \mathrm{s}, \mathrm{CH}_{3}\right), 2.26\left(3 \mathrm{H}, \mathrm{s}, \mathrm{CH}_{3}\right), 7.03-7.97(7 \mathrm{H}$, m, Ar-H), $11.65(1 \mathrm{H}, \mathrm{s}, \mathrm{NH}), 12.22(1 \mathrm{H}, \mathrm{s}, \mathrm{NH}) . \delta_{\mathrm{C}}\left(\mathrm{DMSO}_{6}\right)$ $17.2\left(\mathrm{CH}_{3}\right), 20.6\left(\mathrm{CH}_{3}\right), 20.8\left(\mathrm{CH}_{3}\right), 123.3,126.1,126.8,127.1$, 128.0, 130.1, 130.4, 131.4 133.4, 135.5, 136.7, 148.3 (Ar-C), 166.7 $(\mathrm{C}=\mathrm{O}), 169.1(\mathrm{C}=\mathrm{O})$ and $179.6(\mathrm{C}=\mathrm{S})$.

[2-[(2,6-Dimethylphenyl)carbamothioylcarbamoyl]phenyl] Acetate (4). Compound 4 was obtained as yellowish white solid. Yield: $0.3230 \mathrm{~g}$ (47\%); m.p. 166-169 ${ }^{\circ} \mathrm{C}$; (Found: C, 62.77; H, 5.11; N, 8.00. $\mathrm{C}_{18} \mathrm{H}_{18} \mathrm{O}_{3} \mathrm{~N}_{2} \mathrm{~S}$ Requires $\mathrm{C}, 63.14 ; \mathrm{H}, 5.30 ; \mathrm{N}$, $8.18 \%) ; v 3386(\mathrm{~N}-\mathrm{H}), 1784$ ( $\mathrm{C}=\mathrm{O}$ ester), 1675 ( $\mathrm{C}=\mathrm{O}$ amide), 1504 (Ar-C), $1176(\mathrm{C}-\mathrm{N}), 853(\mathrm{C}=\mathrm{S}) . \delta_{\mathrm{H}}\left(\mathrm{DMSO}_{-} \mathrm{d}_{6}\right) 2.19(6 \mathrm{H}$, $\left.\mathrm{s}, 2 \mathrm{CH}_{3}\right), 2.31\left(3 \mathrm{H}, \mathrm{s}, \mathrm{CH}_{3}\right), 7.12-7.75(7 \mathrm{H}, \mathrm{m}, \mathrm{Ar}-\mathrm{H}), 11.64(2 \mathrm{H}$, s, NH). $\delta_{\mathrm{C}}\left(\mathrm{DMSO}-\mathrm{d}_{6}\right) 17.7\left(\mathrm{CH}_{3}\right), 20.7\left(\mathrm{CH}_{3}\right), 123.0,126.0$, 127.0, 127.5, 128.0, 129.9, 133.2, 135.1, 136.2, 148.1 (Ar-C), 166.4 $(\mathrm{C}=\mathrm{O}), 168.9(\mathrm{C}=\mathrm{O})$ and $179.9(\mathrm{C}=\mathrm{S})$.

[2-[(3-Methylphenyl)carbamothioylcarbamoyl]phenyl] Acetate (5). Compound 5 was obtained as yellow solid. Yield: $0.1177 \mathrm{~g}$ (46\%); m.p 179-181 C; (Found: C, 62.11; H, 4.61; N, 8.28. $\mathrm{C}_{17} \mathrm{H}_{16} \mathrm{O}_{3} \mathrm{~N}_{2} \mathrm{~S}$ Requires $\left.\mathrm{C}, 62.18 ; \mathrm{H}, 4.91 ; \mathrm{N}, 8.53 \%\right) ; v 3382$ (N-H), 1778 (C=O ester), 1660 (C=O amide), 1500 (Ar-C), $1079(\mathrm{C}-\mathrm{N}), 863(\mathrm{C}=\mathrm{S}) . \delta_{\mathrm{H}}\left(\mathrm{DMSO}_{-} \mathrm{d}_{6}\right) 2.32\left(3 \mathrm{H}, \mathrm{s}, \mathrm{CH}_{3}\right), 2.33$ $\left(3 \mathrm{H}, \mathrm{s}, \mathrm{CH}_{3}\right), 7.08-7.73(8 \mathrm{H}, \mathrm{m}, \mathrm{Ar}-\mathrm{H}), 11.60(1 \mathrm{H}, \mathrm{s}, \mathrm{NH}), 12.34$ $(1 \mathrm{H}, \mathrm{s}, \mathrm{NH}) . \delta_{\mathrm{C}}\left(\mathrm{DMSO}_{6} \mathrm{~d}_{6}\right) 20.7\left(\mathrm{CH}_{3}\right), 20.9\left(\mathrm{CH}_{3}\right), 121.3$, 123.2, 124.6, 126.6, 127.0, 125.8, 128.5, 130.0, 133.1, 137.7, 138.1, $148.2($ Ar-C), $166.5(\mathrm{C}=\mathrm{O}), 168.8(\mathrm{C}=\mathrm{O})$ and $178.5(\mathrm{C}=\mathrm{S})$.

[2-[(2,5-Dimethoxyphenyl)carbamothioylcarbamoyl]phenyl] Acetate (6). Compound $\mathbf{6}$ was obtained as light green solid. Yield: $0.1739 \mathrm{~g}(23 \%)$; m.p. $185-186^{\circ} \mathrm{C}$; (Found: C, 57.60; H, $4.40 ; \mathrm{N}, 7.48 . \mathrm{C}_{18} \mathrm{H}_{18} \mathrm{O}_{5} \mathrm{~N}_{2} \mathrm{~S}$ Requires C, 57.74; $\mathrm{H}, 4.85 ; \mathrm{N}$, 7.48\%); $v 3384(\mathrm{~N}-\mathrm{H}), 1777$ ( $\mathrm{C}=\mathrm{O}$ ester), 1611 ( $\mathrm{C}=\mathrm{O}$ amide), 1500 (Ar-C), $1067(\mathrm{C}-\mathrm{N}), 821(\mathrm{C}=\mathrm{S}) . \delta_{\mathrm{H}}\left(\mathrm{DMSO}_{6}\right) 2.31(3 \mathrm{H}$, $\left.\mathrm{s}, \mathrm{CH}_{3}\right), 3.72\left(3 \mathrm{H}, \mathrm{s}, \mathrm{OCH}_{3}\right), 3.84\left(3 \mathrm{H}, \mathrm{s}, \mathrm{OCH}_{3}\right), 7.06-8.50$ $(7 \mathrm{H}, \mathrm{m}, \mathrm{Ar}-\mathrm{H}), 11.62(1 \mathrm{H}, \mathrm{s}, \mathrm{NH}), 12.90(1 \mathrm{H}, \mathrm{s}, \mathrm{NH}) . \delta_{\mathrm{C}}$ $\left(\mathrm{DMSO}_{-} \mathrm{d}_{6}\right) 20.7\left(\mathrm{CH}_{3}\right), 55.5\left(\mathrm{OCH}_{3}\right), 56.6\left(\mathrm{OCH}_{3}\right), 108.9$, $110.5,112.1,123.1,125.9,126.5,127.6,130.1,133.2,144.3,148.2$, 152.4 (Ar-C), $166.5(\mathrm{C}=\mathrm{O}), 168.8(\mathrm{C}=\mathrm{O})$ and $177.0(\mathrm{C}=\mathrm{S})$. 
[2-[(3,4-Dimethoxyphenyl)carbamothioylcarbamoyl]phenyl] Acetate (7). Compound 7 was obtained as dark green solid. Yield: $0.1801 \mathrm{~g}$ (24\%); m.p. $182-184^{\circ} \mathrm{C}$; (Found: C, 57.25; H, 4.62; N, 7.42. $\mathrm{C}_{18} \mathrm{H}_{18} \mathrm{O}_{5} \mathrm{~N}_{2} \mathrm{~S}$ Requires $\mathrm{C}, 57.74 ; \mathrm{H}, 4.85 ; \mathrm{N}$, 7.48\%); $v 3367(\mathrm{~N}-\mathrm{H}), 1791$ ( $\mathrm{C}=\mathrm{O}$ ester), $1670(\mathrm{C}=\mathrm{O}$ amide), $1500\left(\right.$ Ar-C), $1025(\mathrm{C}-\mathrm{N}), 850(\mathrm{C}=\mathrm{S}) . \delta_{\mathrm{H}}\left(\mathrm{DMSO}_{6} \mathrm{~d}_{6}\right) 2.32$ $\left(3 \mathrm{H}, \mathrm{s}, \mathrm{CH}_{3}\right), 3.75\left(3 \mathrm{H}, \mathrm{s}, \mathrm{OCH}_{3}\right), 3.77\left(3 \mathrm{H}, \mathrm{s}, \mathrm{OCH}_{3}\right)$, 6.97-7.41 (7H, m, Ar-H), $11.53(1 \mathrm{H}, \mathrm{s}, \mathrm{NH}), 12.24(1 \mathrm{H}, \mathrm{s}, \mathrm{NH})$. $\delta_{\mathrm{C}}\left(\mathrm{DMSO}-\mathrm{d}_{6}\right) 20.8\left(\mathrm{CH}_{3}\right), 55.7\left(\mathrm{CH}_{3}\right), 108.9,111.5,116.6$, $123.4,126.0,126.7,130.1,130.9,133.3,147.2,148.3,148.4$ (Ar-C), $166.5(\mathrm{C}=\mathrm{O}), 169.0(\mathrm{C}=\mathrm{O})$ and $178.4(\mathrm{C}=\mathrm{S})$.

[2-[(3,5-Dimethoxyphenyl)carbamothioylcarbamoyl]phenyl] Acetate (8). Compound $\mathbf{8}$ was obtained as yellowish white solid. Yield: $0.4190 \mathrm{~g} \mathrm{(56 \% ),} \mathrm{m.p.} 177-179^{\circ} \mathrm{C}$; (Found: C, 57.55; $\mathrm{H}, 4.94 ; \mathrm{N}, 7.61 . \mathrm{C}_{18} \mathrm{H}_{18} \mathrm{O}_{5} \mathrm{~N}_{2} \mathrm{~S}$ Requires $\mathrm{C}$, 57.74; $\mathrm{H}, 4.85 ; \mathrm{N}$, 7.48\%); $v 3382(\mathrm{~N}-\mathrm{H}), 1778$ ( $\mathrm{C}=\mathrm{O}$ ester), $1660(\mathrm{C}=\mathrm{O}$ amide), $1528(\mathrm{Ar}-\mathrm{C}), 1080(\mathrm{C}-\mathrm{N}), 864(\mathrm{C}=\mathrm{S}) . \delta_{\mathrm{H}}\left(\mathrm{DMSO}_{-} \mathrm{d}_{6}\right) 2.31$ $\left(3 \mathrm{H}, \mathrm{s}, \mathrm{CH}_{3}\right), 3.75\left(6 \mathrm{H}, \mathrm{s}, 2 \mathrm{OCH}_{3}\right), 6.42-7.74(7 \mathrm{H}, \mathrm{m}, \mathrm{Ar}-\mathrm{H})$, $11.58(1 \mathrm{H}, \mathrm{s}, \mathrm{NH}), 12.35(1 \mathrm{H}, \mathrm{s}, \mathrm{NH}) . \delta_{\mathrm{C}}\left(\mathrm{DMSO}_{6}\right) 20.8$ $\left(\mathrm{CH}_{3}\right), 55.4\left(2 \mathrm{OCH}_{3}\right), 98.3,102.1,123.3,125.9,126.6,130.1$, 133.2, 139.4, 148.2, 160.3 (Ar-C), $166.4(\mathrm{C}=\mathrm{O}), 168.9(\mathrm{C}=\mathrm{O})$ and $178.2(\mathrm{C}=\mathrm{S})$.

[2-[((4-(Hexyloxy)phenyl)carbamothioyl)carbamoyl]phenyl] Acetate (9). Compound 9 was obtained as yellowish white solid. Yield: $0.2070 \mathrm{~g}(55 \%)$, m.p. $112-119^{\circ} \mathrm{C}$; (Found: C, 63.68; $\mathrm{H}, 6.15 ; \mathrm{N}, 6.91 . \mathrm{C}_{22} \mathrm{H}_{26} \mathrm{O}_{4} \mathrm{~N}_{2} \mathrm{~S}$ Requires $\mathrm{C}, 63.75 ; \mathrm{H}, 6.32 ; \mathrm{N}$, 6.76\%); v $3372(\mathrm{~N}-\mathrm{H}), 2933-2856(\mathrm{C}-\mathrm{H}$ alkyl), $1775(\mathrm{C}=\mathrm{O}$ ester), $1663(\mathrm{C}=\mathrm{O}$ amide), $1527(\mathrm{Ar}-\mathrm{C}), 1106(\mathrm{C}-\mathrm{N}), 829$ $(\mathrm{C}=\mathrm{S}) . \delta_{\mathrm{H}}\left(\mathrm{DMSO}-\mathrm{d}_{6}\right) 0.87\left(3 \mathrm{H}, \mathrm{t}, J=7.3 \mathrm{~Hz}, \mathrm{CH}_{3}\right), 1.31-1.70$ $\left(8 \mathrm{H}, \mathrm{m}, \mathrm{CH}_{2}\right), 2.31\left(3 \mathrm{H}, \mathrm{s}, \mathrm{CH}_{3}\right), 3.96(2 \mathrm{H}, \mathrm{t}, J=6.5 \mathrm{~Hz}$, $\left.\mathrm{OCH}_{2}\right), 6.96-7.73(8 \mathrm{H}, \mathrm{m}, \mathrm{Ar}-\mathrm{H}), 11.54(1 \mathrm{H}, \mathrm{s}, \mathrm{NH}), 12.18(1 \mathrm{H}$, s, NH). $\delta_{\mathrm{C}}\left(\mathrm{DMSO}_{6} \mathrm{~d}_{6}\right) 14.0,20.8,22.1,25.2,28.7,31.0(\mathrm{C}-\mathrm{H}$ alkyl), $67.7\left(\mathrm{OCH}_{2}\right), 114.3,123.3,126.0,126.7,130.1,130.6$, 133.2, 148.3, 157.0 (Ar-C), 166.5 (C=O), $169.0(\mathrm{C}=\mathrm{O})$ and 178.7 $(\mathrm{C}=\mathrm{S})$.

[2-[((4-(Decyloxy)phenyl)carbamothioyl)carbamoyl]phenyl] Acetate (10). Compound 10 was obtained as yellowish white solid. Yield: 0.2400 (51\%), m.p. 116-121 ${ }^{\circ} \mathrm{C}$; (Found: C, 66.13; $\mathrm{H}, 7.44 ; \mathrm{N}, 5.90 . \mathrm{C}_{26} \mathrm{H}_{34} \mathrm{O}_{4} \mathrm{~N}_{2} \mathrm{~S}$ Requires $\mathrm{C}, 66.35 ; \mathrm{H}, 7.28$; N, 5.95\%); $v 3374(\mathrm{~N}-\mathrm{H}), 2923-2849$ (C-H alkyl), $1771(\mathrm{C}=\mathrm{O}$ ester), 1664 ( $\mathrm{C}=\mathrm{O}$ amide), 1510 ( $\mathrm{Ar}-\mathrm{C}), 1111(\mathrm{C}-\mathrm{N}), 826(\mathrm{C}=\mathrm{S})$. $\delta_{\mathrm{H}}\left(\mathrm{DMSO}_{-} \mathrm{d}_{6}\right) 0.85\left(3 \mathrm{H}, \mathrm{t}, J=6.9 \mathrm{~Hz}, \mathrm{CH}_{3}\right), 1.31-1.70(16 \mathrm{H}$, $\left.\mathrm{m}, \mathrm{CH}_{2}\right), 2.31\left(3 \mathrm{H}, \mathrm{s}, \mathrm{CH}_{3}\right), 3.96\left(2 \mathrm{H}, \mathrm{t}, J=6.5 \mathrm{~Hz}, \mathrm{OCH}_{2}\right)$, 6.95-7.73 (8H, m, Ar-H), $11.55(1 \mathrm{H}, \mathrm{s}, \mathrm{NH}), 12.19(1 \mathrm{H}, \mathrm{s}, \mathrm{NH})$. $\delta_{\mathrm{C}}\left(\right.$ DMSO-d $\left._{6}\right) 14.0,20.8,22.1,25.5,28.8,31.3$ (C-H alkyl), $67.6\left(\mathrm{OCH}_{2}\right), 114.3,123.3,125.9,126.6,130.1,130.6,133.2,148.2$, 156.9 $(\mathrm{Ar}-\mathrm{C}), 166.4(\mathrm{C}=\mathrm{O}), 168.9(\mathrm{C}=\mathrm{O})$ and $178.6(\mathrm{C}=\mathrm{S})$.

[2-[((4-(Dodecyloxy)phenyl)carbamothioyl)carbamoyl]phenyl] Acetate (11). Compound $\mathbf{1 1}$ was obtained as yellowish white solid. Yield: 0.2520 (51\%), m.p. 121-124 ${ }^{\circ} \mathrm{C}$; (Found: C, 67.21; $\mathrm{H}, 7.74 ; \mathrm{N}, 5.52 . \mathrm{C}_{28} \mathrm{H}_{38} \mathrm{O}_{4} \mathrm{~N}_{2} \mathrm{~S}$ Requires $\mathrm{C}, 67.44 ; \mathrm{H}, 7.68 ; \mathrm{N}$, 5.62\%); v $3374(\mathrm{~N}-\mathrm{H}), 2923-2843(\mathrm{C}-\mathrm{H}$ alkyl), $1771(\mathrm{C}=\mathrm{O}$ ester), 1664 ( $\mathrm{C}=\mathrm{O}$ amide), 1510 (Ar-C), $1114(\mathrm{C}-\mathrm{N}), 825(\mathrm{C}=\mathrm{S})$. $\delta_{\mathrm{H}}\left(\mathrm{DMSO}_{-} \mathrm{d}_{6}\right) 0.84\left(3 \mathrm{H}, \mathrm{t}, J=6.9 \mathrm{~Hz}, \mathrm{CH}_{3}\right), 1.28-1.68(20 \mathrm{H}$, $\left.\mathrm{m}, \mathrm{CH}_{2}\right), 2.31\left(3 \mathrm{H}, \mathrm{s}, \mathrm{CH}_{3}\right), 3.96\left(2 \mathrm{H}, \mathrm{t}, J=6.5 \mathrm{~Hz}, \mathrm{OCH}_{2}\right)$,
6.94-7.73 (8H, m, Ar-H), $11.55(1 \mathrm{H}, \mathrm{s}, \mathrm{NH}), 12.20(1 \mathrm{H}, \mathrm{s}, \mathrm{NH})$. $\delta_{\mathrm{C}}\left(\right.$ DMSO-d $\left._{6}\right) 14.0,20.8,22.1,25.5,28.8,31.3$ (C-H alkyl), $67.6\left(\mathrm{OCH}_{2}\right), 114.3,123.3,125.8,126.6,130.0,130.5,133.1,148.2$, 156.9 $(\mathrm{Ar}-\mathrm{C}), 166.4(\mathrm{C}=\mathrm{O}), 168.9(\mathrm{C}=\mathrm{O})$ and $178.6(\mathrm{C}=\mathrm{S})$.

[2-[((4-(Tetradecyloxy)phenyl)carbamothioyl)carbamoyl]phenyl] Acetate (12). Compound 12 was obtained as yellowish white solid. Yield: 0.1240 (47\%), m.p. $125-131^{\circ} \mathrm{C}$; (Found: C, 68.08; $\mathrm{H}, 8.23 ; \mathrm{N}, 5.31 . \mathrm{C}_{30} \mathrm{H}_{42} \mathrm{O}_{4} \mathrm{~N}_{2} \mathrm{~S}$ Requires $\mathrm{C}, 68.41 ; \mathrm{H}, 8.04$; N, 5.32\%); v $3375(\mathrm{~N}-\mathrm{H}), 2923-2849$ (C-H alkyl), $1771(\mathrm{C}=\mathrm{O}$ ester), 1663 ( $\mathrm{C}=\mathrm{O}$ amide), 1510 (Ar-C), $1111(\mathrm{C}-\mathrm{N}), 825(\mathrm{C}=\mathrm{S})$. $\delta_{\mathrm{H}}\left(\mathrm{DMSO}_{-} \mathrm{d}_{6}\right) 0.83\left(3 \mathrm{H}, \mathrm{t}, J=6.9 \mathrm{~Hz}, \mathrm{CH}_{3}\right), 1.22-1.69(24 \mathrm{H}$, $\left.\mathrm{m}, \mathrm{CH}_{2}\right), 2.30\left(3 \mathrm{H}, \mathrm{s}, \mathrm{CH}_{3}\right), 3.95\left(2 \mathrm{H}, \mathrm{t}, J=6.5 \mathrm{~Hz}, \mathrm{OCH}_{2}\right)$, 6.94-7.71 (8H, m, Ar-H), $11.53(1 \mathrm{H}, \mathrm{s}, \mathrm{NH}), 12.18(1 \mathrm{H}, \mathrm{s}, \mathrm{NH})$. $\delta_{\mathrm{C}}\left(\mathrm{CDCl}_{3}\right)$ 14.1, 21.3, 22.7, 26.0, 29.6, 31.9 (C-H alkyl), 68.2 $\left(\mathrm{OCH}_{2}\right), 114.6,123.9,124.2,125.7,126.8,130.2,131.4,134.4$, 148.4, $157.9(\mathrm{Ar}-\mathrm{C}), 164.2(\mathrm{C}=\mathrm{O}), 168.3(\mathrm{C}=\mathrm{O})$ and 178.3 $(\mathrm{C}=\mathrm{S})$.

3.2. General Procedure for the Preparation of Alkylated Amines (13-16). 4-Hydroxyl acetanilide (3 mmol) was added to bromoalkanes $(3 \mathrm{mmol})$ in the presence of $\mathrm{K}_{2} \mathrm{CO}_{3}(3 \mathrm{mmol})$ in dry acetone $(20 \mathrm{~mL})$. The mixture was refluxed for $48 \mathrm{~h}$ to obtain white precipitate. Sodium hydroxide $(2 \%, 50 \mathrm{~mL})$ was added and the solid was filtered. The white solid was refluxed for $4 \mathrm{~h}$ in solution of ethanol-HCl (1:1) and extracted using dichloromethane. The organic layer was separated and dried to form 13-16. Supplementary data for FTIR, ${ }^{1} \mathrm{H}$, and ${ }^{13} \mathrm{C}$ NMR spectra of the synthesised compounds are available online.

4-Hexoxyaniline (13). Compound $\mathbf{1 3}$ was obtained as a white crystals. Yield: $1.828 \mathrm{~g}(75 \%)$; m.p. $230-237^{\circ} \mathrm{C} ; v 3408(\mathrm{~N}-\mathrm{H})$, 2934-2866 (-CH), 1517 (Ar-C), $1129(\mathrm{C}-\mathrm{N}) . \delta_{\mathrm{H}}\left(\mathrm{DMSO}_{6} \mathrm{~d}_{6}\right)$ $0.86\left(3 \mathrm{H}, \mathrm{t}, J=6.9 \mathrm{~Hz},-\mathrm{CH}_{3}\right), 1.29-1.69\left(8 \mathrm{H}, \mathrm{m},-\mathrm{CH}_{2}\right), 3.87$ $\left(2 \mathrm{H}, \mathrm{t}, J=6.5 \mathrm{~Hz},-\mathrm{OCH}_{2}\right), 6.84(2 \mathrm{H}, \mathrm{d}, J=9.2 \mathrm{~Hz}, \mathrm{Ar}-$ $\left.\mathrm{H}), 6.91(2 \mathrm{H}, \mathrm{d}, J=8.4 \mathrm{~Hz}, \mathrm{Ar}-\mathrm{H}) . \delta_{\mathrm{C}}\left(\mathrm{DMSO}_{6}\right) \mathrm{d}_{6}\right) 13.9,22.1$, 25.2, 28.7, 31.0 (C-H alkyl), $67.9\left(\mathrm{OCH}_{2}\right), 115.4,120.0,132.4$ and 154.4 (Ar-C).

4-Decoxyaniline (14). Compound $\mathbf{1 4}$ was obtained as a white crystals. Yield: $2.235 \mathrm{~g}(80 \%)$; m.p. $235-244^{\circ} \mathrm{C} ; v 3427(\mathrm{~N}-\mathrm{H})$, 2921-2849 (-CH), $1513\left(\right.$ Ar-C), $1171(\mathrm{C}-\mathrm{N}) . \delta_{\mathrm{H}}\left(\mathrm{DMSO}_{6} \mathrm{~d}_{6}\right)$ $0.84\left(3 \mathrm{H}, \mathrm{t}, J=6.9 \mathrm{~Hz},-\mathrm{CH}_{3}\right), 1.29-1.70\left(16 \mathrm{H}, \mathrm{m},-\mathrm{CH}_{2}\right)$, $3.93\left(2 \mathrm{H}, \mathrm{t}, J=6.6 \mathrm{~Hz},-\mathrm{OCH}_{2}\right), 6.99(2 \mathrm{H}, \mathrm{d}, J=9.2 \mathrm{~Hz}$, $\operatorname{Ar}-\mathrm{H}), 7.27(2 \mathrm{H}, \mathrm{d}, J=9.2 \mathrm{~Hz}, \mathrm{Ar}-\mathrm{H}), 10.15\left(2 \mathrm{H}, \mathrm{s},-\mathrm{NH}_{2}\right)$. $\delta_{\mathrm{C}}\left(\mathrm{DMSO}-\mathrm{d}_{6}\right)$ 14.1, 22.7, 26.0, 29.5, 31.9 (C-H alkyl), 68.2 $\left(\mathrm{OCH}_{2}\right), 115.2,122.3,124.5$ and $159.0(\mathrm{Ar}-\mathrm{C})$.

4-Dodecoxyaniline (15). Compound $\mathbf{1 5}$ was obtained as a white crystals. Yield: $3.050 \mathrm{~g}(87 \%) ;$ m.p. $237-247^{\circ} \mathrm{C}$; $v$ $3434(\mathrm{~N}-\mathrm{H}), 2920-2853(-\mathrm{CH}), 1511(\mathrm{Ar}-\mathrm{C}), 1171(\mathrm{C}-\mathrm{N}) . \delta_{\mathrm{H}}$ $\left(\right.$ DMSO-d $\left._{6}\right) 0.83\left(3 \mathrm{H}, \mathrm{t}, J=6.9 \mathrm{~Hz},-\mathrm{CH}_{3}\right), 1.23-1.71(20 \mathrm{H}$, $\left.\mathrm{m},-\mathrm{CH}_{2}\right), 3.93\left(2 \mathrm{H}, \mathrm{t}, J=6.5 \mathrm{~Hz},-\mathrm{OCH}_{2}\right), 6.99(2 \mathrm{H}, \mathrm{d}$, $J=9.2 \mathrm{~Hz}, \mathrm{Ar}-\mathrm{H}), 7.30(2 \mathrm{H}, \mathrm{d}, J=9.2 \mathrm{~Hz}, \mathrm{Ar}-\mathrm{H}), 10.27(2 \mathrm{H}, \mathrm{s}$, $\left.-\mathrm{NH}_{2}\right) . \delta_{\mathrm{C}}\left(\mathrm{DMSO}-\mathrm{d}_{6}\right) 14.0,22.1,25.5,28.8,31.3$ (C-H alkyl), $67.8\left(\mathrm{OCH}_{2}\right), 115.3,124.1,124.4$ and $158.1(\mathrm{Ar}-\mathrm{C})$. 
4-Tetradecoxyaniline (16). Compound 16 was obtained as a white crystals. Yield: $2.137 \mathrm{~g}(50 \%)$; m.p. 239-248 ${ }^{\circ} \mathrm{C}$; v $3410(\mathrm{~N}-\mathrm{H}), 2919-2853(-\mathrm{CH}), 1512$ (Ar-C), $1171(\mathrm{C}-\mathrm{N}) . \delta_{\mathrm{H}}$ $\left(\mathrm{DMSO}_{-} \mathrm{d}_{6}\right) 0.83\left(3 \mathrm{H}, \mathrm{t}, J=6.9 \mathrm{~Hz},-\mathrm{CH}_{3}\right), 1.23-1.71(24 \mathrm{H}$, $\left.\mathrm{m},-\mathrm{CH}_{2}\right), 3.94\left(2 \mathrm{H}, \mathrm{t}, J=6.3 \mathrm{~Hz},-\mathrm{OCH}_{2}\right), 7.00(2 \mathrm{H}, \mathrm{d}$, $J=9.2 \mathrm{~Hz}, \mathrm{Ar}-\mathrm{H}), 7.30(2 \mathrm{H}, \mathrm{d}, J=9.8 \mathrm{~Hz}, \mathrm{Ar}-\mathrm{H}), 10.21(2 \mathrm{H}, \mathrm{s}$, $\left.-\mathrm{NH}_{2}\right) . \delta_{\mathrm{C}}\left(\mathrm{DMSO}_{6}\right)$ 13.9, 22.1, 25.2, 28.7, 31.0 (C-H alkyl), $67.9\left(\mathrm{OCH}_{2}\right), 115.4,120.0,132.4$ and 154.4 (Ar-C).

\subsection{Antibacterial Studies}

3.3.1. Turbidimetric Kinetic Method. The antibacterial activities of the synthesised compounds were initially studied using turbidimetric kinetic method against E. coli bacteria ATCC 25922 and $S$. aureus S48/81. The inoculums were allowed to grow at $37^{\circ} \mathrm{C}$ with permanent stirring at $150 \mathrm{rpm}$ overnight in Luria-Bertani broth. $0.2 \mathrm{~mL}$ of inoculums was inoculated with $10 \mathrm{~mL}$ of culture medium at increasing concentration of the compounds (50, 80, and $100 \mathrm{ppm}$ ) dissolved in DMSO. The mixtures were shaken at $150 \mathrm{rpm}$ at $37^{\circ} \mathrm{C}$. The inoculum with only DMSO mixture was used as control. The aliquots of each replicate were taken at $1 \mathrm{~h}$ interval for $6 \mathrm{~h}$. UV/Visible spectrometer Optima SP-300 was used to analyse the amount of transmittance $(T)$. The antibacterial activities of the compounds were determined from the graph as $\ln N_{t}$ versus time. $N_{t}$ is related to the number of colony forming units $/ \mathrm{mL}$. The $\ln N_{t}$ values were calculated based on the formula of $\ln N_{t}=27.1-8.56 T$ (E. coli) and $\ln N_{t}=27.4-10.3 T$ (S. aureus) [35].

3.3.2. Disc Diffusion Method. Disc diffusion method was used due to the insolubility of compounds in medium. $E$. coli ATCC 25922 and S. aureus S48/81 were used as inoculum where they were cultured in Mueller-Hinton broth and incubated at $37^{\circ} \mathrm{C}$ with permanent shaking at $150 \mathrm{rpm}$ overnight. The bacterial suspension was then inoculated onto the entire surface of a Mueller-Hinton agar plate with a sterile cotton-tipped swab to form an even lawn. Sterile filter paper disc impregnated with $10 \mu \mathrm{L}$ of the compound in DMSO was placed on the surface of agar plate using a sterile pair of forceps. The plates were then incubated at $37^{\circ} \mathrm{C}$ for $24 \mathrm{~h}$. The zones of inhibition were measured in millimetre $(\mathrm{mm})$ to estimate the potency of the test compounds [29].

\section{Conclusion}

A series of aspirin derivatives 1-12 with various types of carbon substituents were successfully synthesised and demonstrated against $E$. coli and $S$. aureus. The compounds showed moderate to excellent antibacterial activities compared to aspirin alone. The substituents at meta position gave better activity compared to ortho and para position. Aspirin derivative with shorter chain length showed moderate activity, compared to the longer alkyl chain. The properties of the substituents have contributed to the activities and potential usage in pharmaceutical industries.

\section{Competing Interests}

The authors declare that there are no competing interests regarding the publication of this paper.

\section{Acknowledgments}

The authors would like to thank Universiti Malaysia Sarawak and Malaysia Ministry of Education for Research Funds FRGS/ST01(02)/968/2013(09) and FRGS/ST02(01)/1115/2014 (01).

\section{References}

[1] Y. Gülkok, T. Biçer, F. K. Onurdağ, S. Özgen, M. F. Şahin, and D. S. Doğruer, "Synthesis of some new urea and thiourea derivatives and evaluation of their antimicrobial activities," Turkish Journal of Chemistry, vol. 36, no. 2, pp. 279-291, 2012.

[2] E. Rubin and H. M. Reisner, Eds., Essentials of Rubin's Pathology, Lippincott Williams \& Wilkins, Philadelphia, Pa, USA, 5th edition, 2009.

[3] R. Richard-Kortum, Biomedical Engineering for Global Health, Cambridge University Press, Cambridge, Mass, USA, 2010.

[4] K. L. Williamson, Macroscale and Microscale Organic Experiments, Houghton Mifflin, Boston, Mass, USA, 2nd edition, 1994.

[5] Z. Ngaini, M. A. Mohd Arif, H. Hussain, E. S. Mei, D. Tang, and D. H. A. Kamaluddin, "Synthesis and antibacterial activity of acetoxybenzoyl thioureas with aryl and amino acid side chains," Phosphorus, Sulfur and Silicon and the Related Elements, vol. 187, no. 1, pp. 1-7, 2012.

[6] A. Lawal and J. A. Obaleye, "Synthesis, characterization and antibacterial activity of aspirin and paracetamol-metal complexes," Biokemistri, vol. 19, no. 1, pp. 9-15, 2007.

[7] B. B. Chavan, P. D. Chitte, N. P. Choudhary, K. G. Albhar, and V. I. Hukkeri, "Synthesis and biological evaluation of novel benzimidazole derivative with aspirin as potent antimicrobial \& antifungal agents," International Journal of Scientific Research and Reviews, vol. 1, pp. 22-30, 2012.

[8] A. Bratasz, K. Selvendiran, T. Wasowicz et al., "NCX-4040, a nitric oxide-releasing aspirin, sensitizes drug-resistant human ovarian xenograft tumors to cisplatin by depletion of cellular thiols," Journal of Translational Medicine, vol. 6, article 9, 2008.

[9] S. Joseph, T. Nie, L. Huang et al., "Structure-activity relationship study of novel anticancer aspirin-based compounds," Molecular Medicine Reports, vol. 4, no. 5, pp. 891-899, 2011.

[10] Z. Zhong, R. Xing, S. Liu, L. Wang, S. Cai, and P. Li, "Synthesis of acyl thiourea derivatives of chitosan and their antimicrobial activities in vitro," Carbohydrate Research, vol. 343, no. 3, pp. 566-570, 2008.

[11] A. A. Isab, S. Nawaz, M. Saleem et al., "Synthesis, characterization and antimicrobial studies of mixed ligand silver (I) complexes of thioureas and triphenylphosphine; crystal structure of $\left[\mathrm{Ag}\left(\mathrm{PPh}_{3}\right)\right.$ (thiourea $\left.)\left(\mathrm{NO}_{3}\right)\right]_{2}\left[\mathrm{Ag}\left(\mathrm{PPh}_{3}\right) \text { (thiourea) }\right]_{2}\left(\mathrm{NO}_{3}\right)_{2}$," Polyhedron, vol. 29, no. 4, pp. 1251-1256, 2010.

[12] W. S. H. Wan Zullkiplee, A. N. Abd Halim, Z. Ngaini, M. A. Mohd Ariff, and H. Hussain, "Bis-thiourea bearing aryl and amino acids side chains and their antibacterial activities," Phosphorus, Sulfur and Silicon and the Related Elements, vol. 189, no. 6, pp. 832-838, 2014.

[13] R. D. Campo, J. J. Criado, R. Gheorghe et al., "N-benzoyl$\mathrm{N}$ /-alkylthioureas and their complexes with $\mathrm{Ni}(\mathrm{II}), \mathrm{Co}(\mathrm{III})$ 
and Pt(II)-crystal structure of 3-benzoyl-1-butyl-1-methylthiourea: activity against fungi and yeast," Journal of Inorganic Biochemistry, vol. 98, no. 8, pp. 1307-1314, 2004.

[14] S. Saeed, N. Rashid, P. G. Jones, M. Ali, and R. Hussain, "Synthesis, characterization and biological evaluation of some thiourea derivatives bearing benzothiazole moiety as potential antimicrobial and anticancer agents," European Journal of Medicinal Chemistry, vol. 45, no. 4, pp. 1323-1331, 2010.

[15] D. Sriram, P. Yogeeswari, and M. Madhu, "Synthesis and in vitro antitubercular activity of some 1-[(4-sub)phenyl]-3(4-1-[(pyridine-4-carbonyl) hydrazono] ethylphenyl) thiourea," Bioorganic \& Medicinal Chemistry Letters, vol. 16, pp. 868-878, 2006.

[16] A. Saeed, U. Shaheen, A. Hameed, and S. Z. H. Naqvi, "Synthesis, characterization and antimicrobial activity of some new 1(fluorobenzoyl)-3-(fluorophenyl)thioureas," Journal of Fluorine Chemistry, vol. 130, no. 11, pp. 1028-1034, 2009.

[17] I. Küçükgüzel, E. Tatar, Ş. G. Küçükgüzel, S. Rollas, and E. De Clercq, "Synthesis of some novel thiourea derivatives obtained from 5-[(4-aminophenoxy)methyl]-4-alkyl/aryl-2,4-dihydro3H-1,2,4-triazole-3-thiones and evaluation as antiviral/antiHIV and anti-tuberculosis agents," European Journal of Medicinal Chemistry, vol. 43, no. 2, pp. 381-392, 2008.

[18] C. Alkan, Y. Tek, and D. Kahraman, "Preparation and characterization of a series of thiourea derivatives as phase change materials for thermal energy storage," Turkish Journal of Chemistry, vol. 35, no. 5, pp. 769-777, 2011.

[19] A. M. Alkherraz, Z. I. Lusta, and A. E. Zubi, "Synthesis and use of thiourea derivative (1-phenyl-3-benzoyl-2-thiourea) for extraction of cadmium ion," International Journal of Chemical, Nuclear, Materials and Metallurgical Engineering, vol. 8, pp. 116118, 2014.

[20] C. Kaya, M. Ashraf, and O. Sönmez, "Promotive effect of exogenously applied thiourea on key physiological parameters and oxidative defense mechanism in salt-stressed Zea mays L. plants," Turkish Journal of Botany, vol. 39, no. 5, pp. 786-795, 2015.

[21] A. N. Cammidge, S. Downing, and Z. Ngaini, "Surface-functionalised nano-beads as novel supports for organic synthesis," Tetrahedron Letters, vol. 44, no. 35, pp. 6633-6634, 2003.

[22] A. R. Katritzky, S. Ledoux, R. M. Witek, and S. K. Nair, "1-(Alkyl/Arylthiocarbamoyl)benzotriazoles as stable isothiocyanate equivalents: synthesis of $\mathrm{Di}$ - and trisubstituted thioureas," The Journal of Organic Chemistry, vol. 69, no. 9, pp. 2976-2982, 2004.

[23] R. Rahamathulla, W. M. Khairul, H. Salleh, H. K. Adli, M. I. N. Isa, and M. G. Tay, "Synthesis, characterization and electrochemical analysis of V-shaped disubstituted thioureachlorophyll thin film as active layer in organic solar cells," International Journal of Electrochemical Science, vol. 8, no. 3, pp. 3333-3348, 2013.

[24] S. Saeed, N. Rashid, M. Ali, R. Hussain, and P. G. Jones, "Synthesis, spectroscopic characterization, crystal structure and pharmacological properties of some novel thiophene-thiourea core derivatives," European Journal of Chemistry, vol. 1, no. 3, pp. 221-227, 2010.

[25] M. S. M. Yusof, R. H. Jusoh, W. M. Khairul, and B. M. Yamin, "Synthesis and characterisation a series of $N$-(3,4-dichlorophenyl)-NI-(2,3 and 4-methylbenzoyl)thiourea derivatives," Journal of Molecular Structure, vol. 975, no. 1-3, pp. 280-284, 2010.
[26] N. Cheng, W.-B. Yi, Q.-Q. Wang, S.-M. Peng, and X.-Q. Zou, "Synthesis and $\alpha$-glucosidase inhibitory activity of chrysin, diosmetin, apigenin, and luteolin derivatives," Chinese Chemical Letters, vol. 25, no. 7, pp. 1094-1098, 2014.

[27] Z. Ngaini, S. M. Haris Fadzillah, and H. Hussain, "Synthesis and antimicrobial studies of hydroxylated chalcone derivatives with variable chain length," Natural Product Research, vol. 26, no. 10, pp. 892-902, 2012.

[28] T. W. G. Solomons and C. B. Fryhle, Organic Chemistry, John Wiley \& Sons, New York, NY, USA, 8th edition, 2004.

[29] L. K. Soni, T. Narsinghani, and R. Jain, "Synthesis and antibacterial screening of some 1-aroyl-3-aryl thiourea derivatives," ISRN Medicinal Chemistry, vol. 2014, Article ID 393102, 6 pages, 2014.

[30] K. Petnapapun, W. Chavasiri, and P. Sompornpisut, "Structure-activity relationships of 3,3/-phenylmethylene-bis-4-hydroxycoumarins: selective and potent inhibitors of grampositive bacteria," The Scientific World Journal, vol. 2013, Article ID 178649, 11 pages, 2013.

[31] E. Rodríguez-Fernández, J. L. Manzano, J. J. Benito, R. Hermosa, E. Monte, and J. J. Criado, "Thiourea, triazole and thiadiazine compounds and their metal complexes as antifungal agents," Journal of Inorganic Biochemistry, vol. 99, no. 8, pp. 1558-1572, 2005.

[32] C. R. Birnie, D. Malamud, and R. L. Schnaare, "Antimicrobial evaluation of $N$-Alkyl betaines and $N$-Alkyl-N,Ndimethylamine oxides with variations in chain length," Antimicrobial Agents and Chemotherapy, vol. 44, no. 9, pp. 2514-2517, 2000.

[33] J. Li, X. Rao, S. Shang, Y. Gao, and J. Song, "Synthesis and antibacterial activity of amide derivatives from acrylopimaric acid," BioResources, vol. 7, no. 2, pp. 1961-1971, 2012.

[34] J. C. Lopez-Romero, H. González-Ríos, A. Borges, and M. Simões, "Antibacterial effects and mode of action of selected essential oils components against Escherichia coli and Staphylococcus aureus," Evidence-based Complementary and Alternative Medicine, vol. 2015, Article ID 795435, 9 pages, 2015.

[35] N. B. Pappano, O. P. Centorbi, and F. H. Ferreti, "Determination of minimum concentration inhibitory chalcone derivatives," Revise Microbiology, vol. 2, pp. 183-188, 1990. 

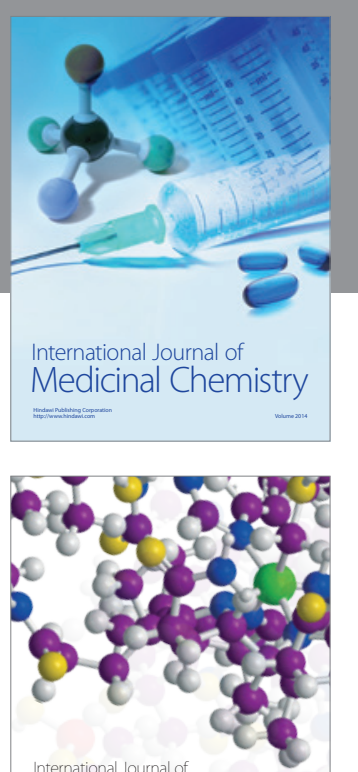

Carbohydrate Chemistry

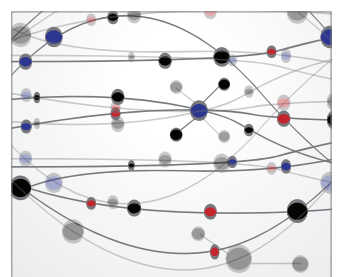

The Scientific World Journal
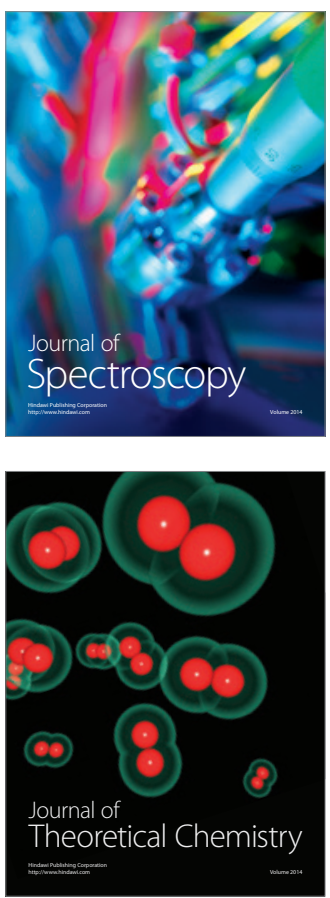
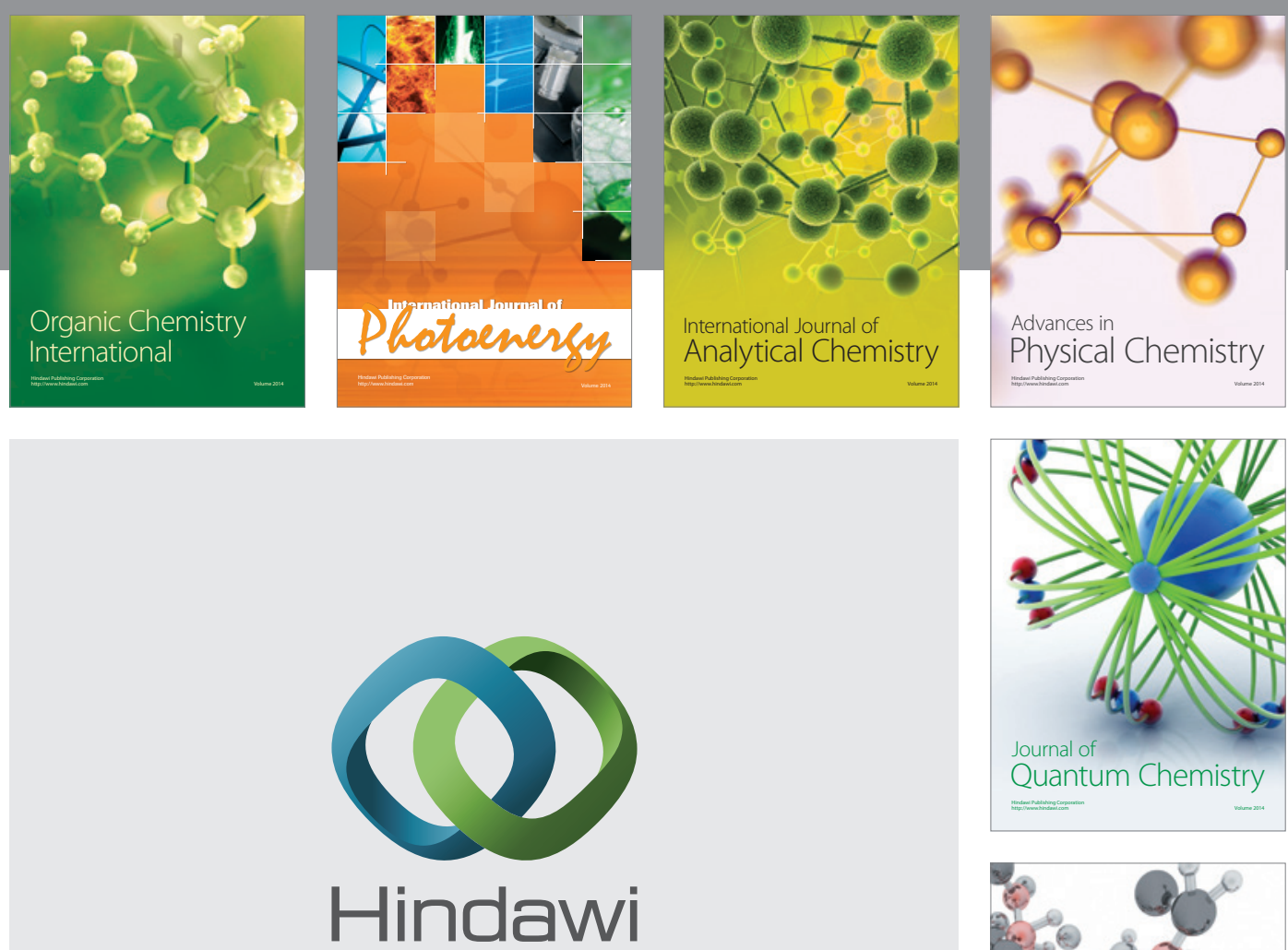

Submit your manuscripts at

https://www.hindawi.com

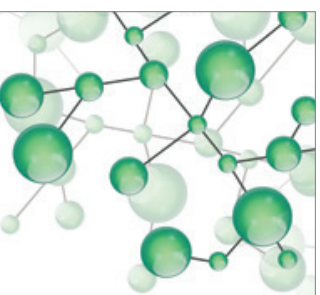

International Journal of

Inorganic Chemistry
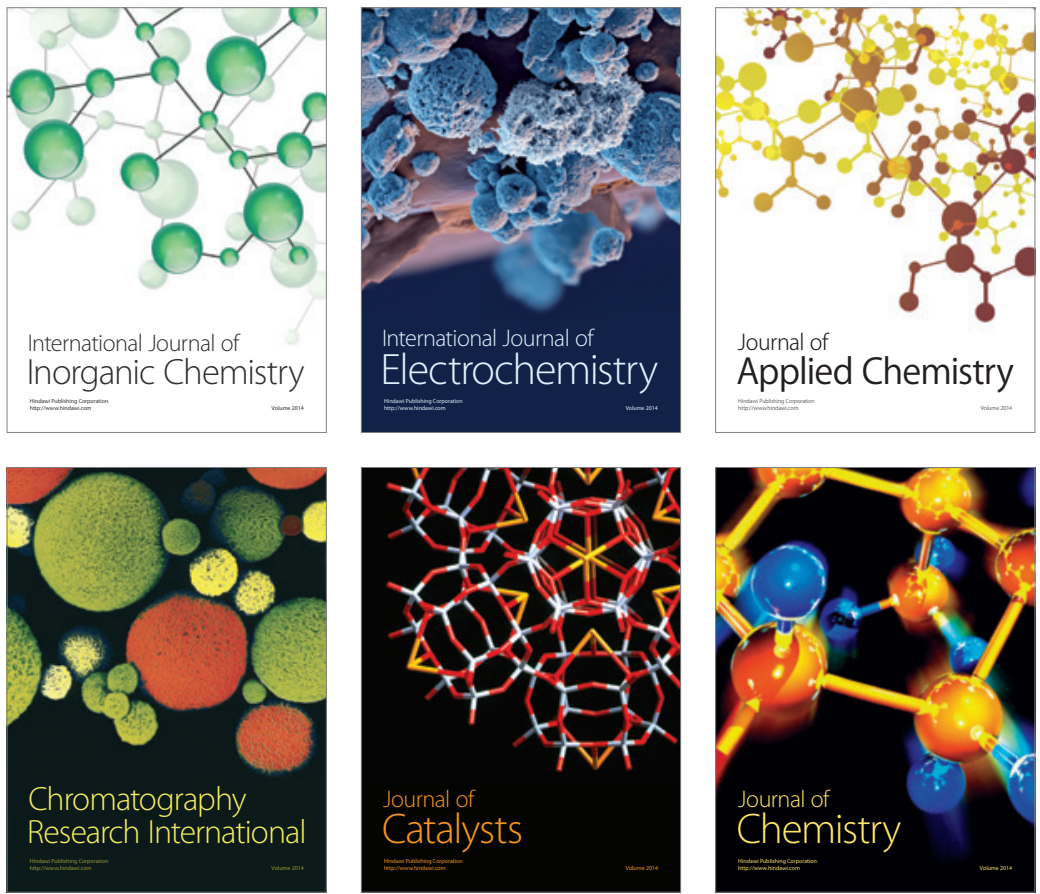

Journal of

Applied Chemistry
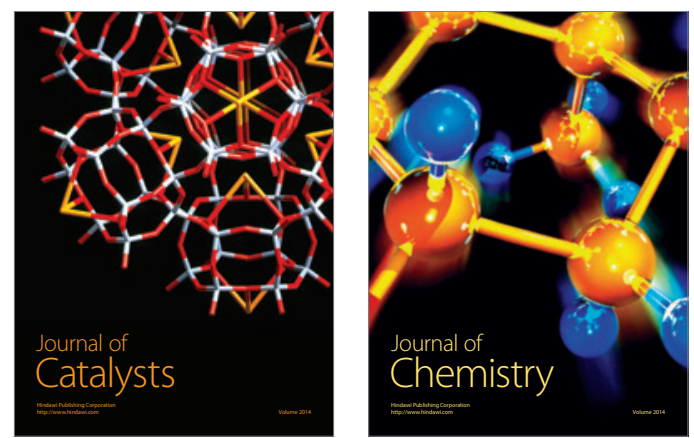
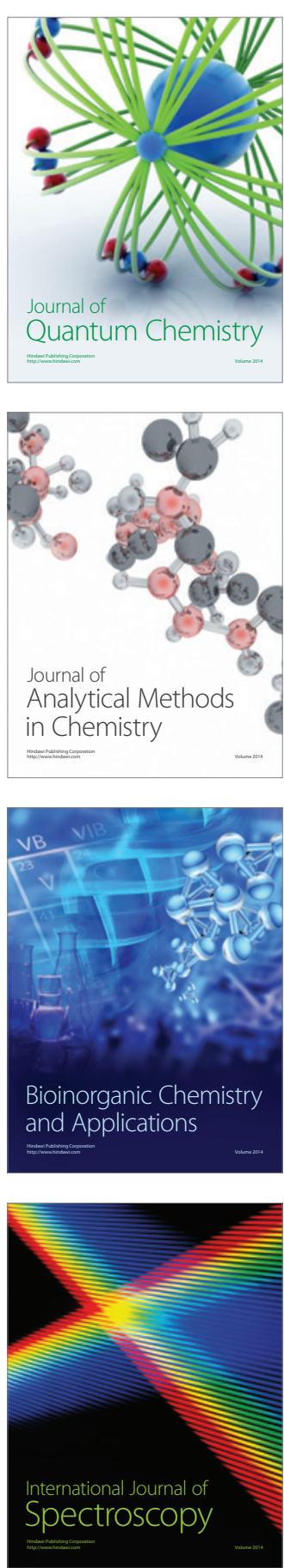